\title{
Identification of a novel CHEK2 variant and assessment of its contribution to the risk of breast cancer in French Canadian women David J Novak ${ }^{1,2,3}$, Long Qi Chen ${ }^{1,4}$, Parviz Ghadirian ${ }^{5}$, Nancy Hamel ${ }^{1,6}$, Phil Zhang7, Vanessa Rossiny ${ }^{6}$, Guy Cardinal ${ }^{8,9}$, André Robidoux ${ }^{10}$, Patricia N Tonin ${ }^{1,2,6}$, Francois Rousseau ${ }^{8,9}$, Steven A Narod ${ }^{7}$ and William D Foulkes*1,2,3,6,8
}

\begin{abstract}
Address: ${ }^{1}$ Program in Cancer Genetics, Departments of Oncology and Human Genetics McGill University, Montreal, QC, H2W 1S6, Canada, ${ }^{2}$ Departments of Medicine and Human Genetics, McGill University, Montreal, QC, H2W 1S6, Canada, ${ }^{3}$ Segal Cancer Center, McGill University Sir M. B. Davis-Jewish General Hospital, 3755 Cote Ste-Catherine, Montreal, QC, H3T 1E2, Canada, ${ }^{4}$ Department of Thoracic and Cardiovascular Surgery, West China Hospital, Sichuan University, Chengdu 610041, PR China, ${ }^{5}$ Epidemiology Research Unit, Research Centre, Centre Hospitalier Université de Montréal, 3850 St-Urbain, Montréal, QC, H2W 1T7, Canada, ${ }^{6}$ The Research Institute, McGill University Health Centre, 1650 Cedar Avenue, Montréal, QC, H3G 1A4, Canada, ${ }^{7}$ Women's College Research Institute, University of Toronto, 790 Bay Street, Toronto, ON, M5G 1N8, Canada, ${ }^{8}$ The CanGènetest Research Consortium on genetic Laboratory Services, Centre de recherché du CHUQ/HSFA, 10 rue de l'Espinay, Québec, QC, G1L 3L, Canada, ${ }^{9}$ Centre de recherché du CHUQ - Hôpital St-François d'Assise, Centre Hospitalier Université de laval, 10 rue de l'Espinay, Québec, QC, G1L 3L5, Canada and ${ }^{10}$ Department of Surgery, Centre Hospitalier Université du Montréal, 3850 St-Urban, Montréal, QC, H2W 1T7, Canada

Email: David J Novak - david.novak@mail.mcgill.ca; Long Qi Chen - drchenlq@hotmail.com; Parviz Ghadirian - parviz.ghadirian@umontreal.ca; Nancy Hamel - nancy.hamel@mail.mcgill.ca; Phil Zhang - phil.zhang@utoronto.ca; Vanessa Rossiny - vanessa.rossiny@voila.fr; Guy Cardinal - Guy.Cardinal@hotmail.com; André Robidoux - andre.robidoux.chum@ssss.gouv.qc.ca; Patricia N Tonin - patricia.tonin@mcgill.ca; Francois Rousseau - francois.rousseau@mac.com; Steven A Narod - Steven.Narod@wchospital.ca; William D Foulkes* - william.foulkes@mcgill.ca

* Corresponding author
\end{abstract}

Published: 15 August 2008

BMC Cancer 2008, 8:239 doi:10.1 186/147|-2407-8-239
Received: 25 February 2008

Accepted: 15 August 2008

This article is available from: http://www.biomedcentral.com//47/-2407/8/239

(C) 2008 Novak et al; licensee BioMed Central Ltd.

This is an Open Access article distributed under the terms of the Creative Commons Attribution License (http://creativecommons.org/licenses/by/2.0), which permits unrestricted use, distribution, and reproduction in any medium, provided the original work is properly cited.

\begin{abstract}
Background: $B R C A I$ and $B R C A 2$ account for the majority of the known familial breast cancer risk, however, the impact of other cancer susceptibility genes largely remains to be elucidated. Checkpoint Kinase 2 (CHEK2) is an important signal transducer of cellular responses to DNA damage, whose defects have been associated with an increase in breast cancer risk. Previous studies have identified low penetrance CHEK2 alleles such as I I00delC and II57T, as well as variants such as $\mathrm{S428F}$ in the Ashkenazi Jewish population and IVS2 + IG>A in the Polish population. No founder allele has been specifically identified in the French Canadian population.
\end{abstract}

Methods: The 14 coding exons of CHEK2 were fully sequenced for variant alleles in a panel of 25 affected French Canadian women and 25 healthy controls. Two variants were identified of which one novel variant was further screened for in an additional panel of 667 breast cancer patients and 6548 healthy controls. Additional genotyping was conducted using allele specific PCR and a restriction digest assay. Significance of amino acid substitutions were deduced by employing comparative analysis techniques.

Results: Two variants were identified: the previously reported silent substitution 252A>G (E84E) and the novel missense variant, $1217 \mathrm{G}>\mathrm{A}(\mathrm{R} 406 \mathrm{H})$. No significant difference in allele distribution 
between French Canadian women with breast cancer and healthy controls was observed (3/692, $0.43 \%$ vs. $22 / 6573,0.33 \%$, respectively, $P=0.73$ ).

Conclusion: The novel CHEK2 missense variant identified in this study, $\mathrm{R} 406 \mathrm{H}$, is unlikely to contribute to breast cancer risk in French Canadian women.

\section{Background}

Breast cancer is the most common form of malignancy amongst females in the western world. Specifically, one in ten of all new diagnosed cancer cases are of the female breast [1]. Typically, less than five percent of these cases are inherited in a mendelian fashion, specifically from the segregation of highly penetrant alleles, such as mutations in BRCA1 and BRCA2 [2]. The existence of a large number of breast cancer families who lack linkage to either BRCA1 or BRCA2 [3] suggested that other breast cancer susceptibility genes remained undiscovered. One such candidate gene, CHEK2, encodes a multifunctional kinase enzyme involved in the induction of cell cycle arrest, DNA repair and apoptosis [4-6]. Several large-scale studies have characterized known variants of the CHEK2 gene [7-9], conclusively proving that CHEK2 is a breast cancer susceptibility gene.

One CHEK2 mutation present in the general population, 1100 delC, occurs independently of BRCA1/2 mutations $[7,8]$. The 1100 delC variant results in a premature stop codon within exon 10, impairing the kinase ability of the enzyme and resulting in a two-fold increase in breast cancer risk $[7,8,10]$. In general, the population frequency of 1100 delC has been reported to be $\sim 1.9 \%$ in individuals with breast cancer, compared to $\sim 0.7 \%$ in those without [10]. There is, however, variation in the observed frequency of 1100delC [10-13] suggesting that the prevalence of this mutation varies amongst populations.

Population isolates, also known as founder populations, have reduced genetic heterogeneity and are valuable tools for genetic analysis involving cancer susceptibility. A recent example of such an approach has been seen with the identification of the CHEK2 S428F mutation in the Ashkenazi Jewish population, which has been associated with a relative breast cancer risk of 2.0 amongst Ashkenazi Jewish women [14]. Similarly, a splice site mutation, IVS2 $+1 \mathrm{G}>\mathrm{A}$, originally identified in a US patient with familial prostate cancer [15], has been identified as a founder mutation in the Polish population with a population frequency of $0.3 \%$ [16]. The allele is associated with a twoto four-fold elevated risk for prostate, as well as a moderate increase in risk for breast cancer $[16,17]$. Most recently, Walsh et al. [18] discovered a novel 5.4 Kb deletion, leading to a loss of exons 9 and 10, in two families of Central European ancestry. This mutation was found in $1.3 \%$ of 631 patients and in none of the 367 healthy controls. Fur- ther analysis of CHEK2 may reveal additional founder mutations in other populations. One such population yet to be investigated, and the focus of this study, is the French Canadian population.

Established in Quebec between 1608 and 1760, the population now includes approximately 6 million French Canadians, who are descendants of an estimated 800010000 migrants from France [19]. Altogether, approximately $80 \%$ of these founders still have descendants in Quebec today, and they account for the major part of the French Canadian gene pool [20]. Many of the hereditary disorders in the French Canadian population show evidence of founder effects (for review, see [19]). In particular, French Canadian founder mutations have been identified in BRCA1, BRCA2 and PALB2 [21-24].

In the current study, we examined a panel of 25 BRCA1/2 negative, affected French Canadian women alongside 25 healthy controls, to investigate the impact of $\mathrm{CHEK} 2$ variants on breast cancer susceptibility in the French Canadian population.

\section{Methods \\ Study Population}

French Canadian women, previously affected by breast cancer, and determined through sequencing to be negative for all exonic BRCA1 and BRCA2 mutations, were used for SNP discovery $(n=25)$. Cases had a family history of breast cancer with at least three cases of either breast cancer diagnosed before 65 years of age, male breast cancer, or ovarian cancer within three degrees from the index case [21]. Healthy French Canadian women with unknown BRCA1/2 mutation status were used as controls $(n=25)$. Controls were requited either through random dialing or as spouses of cases ascertained for previous studies of cancer, in the French Canadian population (Group 1, $\mathrm{n}=50$ ).

Variants identified in the initial case/control group were further screened for in extended groups of breast cancer cases and unaffected controls, using the original carrier samples as a positive control. Group 2 consists of cases ( $n$ = 124) which were tested, and found negative, for French Canadian BRCA1/2 mutations reported by Tonin et al [21]. Women included in this group were diagnosed at a mean age of 54 (range $=26-76$ ) years old and were referred to cancer genetics clinics at McGill University hos- 
pitals. Patients included in Group 2 were selected for either a high risk family history of at least three cases of breast and/or ovarian cancer within three degrees from the index case, or for presentation of multiple consecutive breast cancer cases prior to the age of 76. Cases included in this panel were genotyped alongside a subset of healthy French Canadian women, recruited through random dialing, in the clinic or as spouses of cases from previous investigations, as controls $(\mathrm{n}=116)$. Group 3 includes an extended group of French Canadian women $(n=543)$ previously diagnosed with breast cancer at Hotel-Dieu Hospital, Montreal, at a mean age of 47 (range $=26-65$ ) years old. All women in this group had previously been tested and found negative for French Canadian BRCA1/2 founder mutations. Recruited patients were either under 50 years of age at diagnosis, or were diagnosed between 50 and 65 and had a first degree relative with breast cancer. Group 4 consists of a panel of French Canadian neonatal controls $(\mathrm{n}=6432)$, which have been previously tested for several known PALB2 variants [24] as well as the known BRCA1 and BRCA2 French Canadian founder mutations.

All patients have provided written consent to participate in current research based investigations. The study is in compliance with the Helsinki declaration, and has been granted ethical approval by the institutional review boards of McGill University and the University of Toronto.

\section{Molecular methods Genotyping}

SNP discovery was performed on Group 1 by direct PCR and sequencing (sequencing was conducted by the McGill University and Genome Quebec Innovation Center in both the forward and reverse directions). Sequencing was performed on all of the 14 coding exons of CHEK2 as well as at the intron/exon boundaries. Primers used for PCR were designed using the online Primer3 program (Primer3). All primers used, annealing temperatures and amplicon sizes are summarized in Table 1.

\section{Long Range PCR}

Any variants found within exons 10-14, which are known to be duplicated wholly or in part on various chromosomes, were reamplified via long range PCR; a $9.2 \mathrm{~Kb}$ fragment encompassing exons 10-14 was generated using primers F5'-CGACGGCCAGTCTCAAGAAGAGGACTGTCTT-3' and R5'-GCTATGACCATGCACAAAGCCCAGGTTCCATC-3' as previously described [14]. PCR was conducted using the Expand Long Template PCR system (Roche Applied Science, Cat No. 1-681-834) with an annealing temperature of $58^{\circ} \mathrm{C}$.
Products obtained from Long-range PCR were then used as a template in a second round of amplification, using appropriate primers to isolate individual exons for sequencing.

\section{Allele-Specific PCR}

To determine the frequency of $1217 \mathrm{G}>\mathrm{A}$ in Group 2, a forward primer with the last nucleotide specific to the variant was designed and used in conjunction with the exon 10 primers designed for sequencing. PCR was conducted at an annealing temperature of $54^{\circ} \mathrm{C}$ and the product was visualized by gel electrophoresis.

Allele-specific amplification was preformed as above for Group 4 which was followed by fluorometric detection of the PCR product using SybrGreen. A scatter plot was derived from the raw fluorescence of both alleles which was then analyzed to compute the genotype as previously described [25]. The accuracy of this method is $99.0 \%$ and the average rate of data rejection is below $1.00 \%$.

\section{Restriction Assay}

Samples from Group 3 were genotyped via a restriction digest assay. Samples were amplified by PCR twice: the first to isolate CHEK2 exon 10, and the second using nested primers to obtain a smaller fragment of $202 \mathrm{bp}$, encompassing $1217 \mathrm{G}>\mathrm{A}$. Products obtained from the second round of amplification were incubated overnight at $37^{\circ} \mathrm{C}$ with +NlaIII $(1 \mathrm{U} /$ sample, New England BioLabs, USA). NlaIII digests after the consensus sequence of CATG, and thus cut the variant (A) allele, resulting in three fragments of 4, 76 and $122 \mathrm{bp}$, respectively. After digest, the wildtype CHEK2 allele results in two fragments of 4 and $198 \mathrm{bp}$, respectively. A sample mutant for R406H (confirmed by sequencing) and a wild-type sample were randomly seeded on each 96-well plate and used as positive and negative controls respectively in the screening process. Digested products were visualized by gel electrophoresis. The presence of $1217 \mathrm{G}>\mathrm{A}$ was confirmed by direct sequencing using the BigDye ${ }^{\circledast}$ Terminator v1.1 Cycle Sequencing Kit and $3130 \times 1$ Genetic Analyzer (Applied Biosystems, USA).

\section{I lo0delC mutation Analysis}

The presence of 1100delC within samples encompassing Group 2 was determined by generating S-35 labeled PCR products. PCR product was denatured for $15 \mathrm{~min}$ at $95^{\circ} \mathrm{C}$ prior to loading in a 5\% denaturing polyacrylamide gel. PCR products were separated for 2 hours at $80 \mathrm{~W}$ and visualized by audioradiography.

\section{Amino Acid stability, conservation and severity}

To estimate the impact of amino acid substitutions on phenotype, mean chemical distance between the wild type amino acid and its substitute was evaluated using the 
Table I: CHEK2 Primers and Details

\begin{tabular}{|c|c|c|c|c|c|}
\hline Fragment & Size (bp) & Exon & Amino Acid & Primers (5'->3') & $\begin{array}{l}\text { Annealing } \\
\text { Temp. }\left({ }^{\circ} \mathrm{C}\right)\end{array}$ \\
\hline CHEK2EXOI & 565 & I & $1-106$ & $\begin{array}{l}\text { Forward: gaactataggtctggggctgttagg } \\
\text { Reverse: tccacctggtaatacaactttctg }\end{array}$ & 57 \\
\hline CHEK2EX02 & 582 & $2 \& 3$ & $107-197$ & $\begin{array}{l}\text { Forward: tgccttcttaggctattttcctac } \\
\text { Reverse: aaccatattctgtaaggacaggac }\end{array}$ & 56 \\
\hline CHEK2EX04 & 354 & 4 & $198-228$ & $\begin{array}{l}\text { Forward: ctcaagggctttacaatatg } \\
\text { Reverse: gaaatgagaaaccaccaatc }\end{array}$ & 54 \\
\hline CHEK2EX05 & 499 & 5 & $229-264$ & $\begin{array}{l}\text { Forward: gaatttcacaatccaggggctac } \\
\text { Reverse: ctcacaaattcatccatctaagcag }\end{array}$ & 56 \\
\hline CHEK2EX06 & 632 & 6 & $265-282$ & $\begin{array}{l}\text { Forward: tagagctgggtttggaactcag } \\
\text { Reverse: agctaggcatgtgtgtgaatg }\end{array}$ & 68 \\
\hline CHEK2EX07 & 434 & 7 & $283-304$ & $\begin{array}{l}\text { Forward: aagaagactgggaagagacctagc } \\
\text { Reverse: gcaagcctacattagattctttgg }\end{array}$ & 56 \\
\hline CHEK2EX08 & 365 & 8 & $305-336$ & $\begin{array}{l}\text { Forward: catctcattccttagtttccaactg } \\
\text { Reverse: tctgcctaattcagggagtaattc }\end{array}$ & 56 \\
\hline CHEK2EX09 & 331 & 9 & $337-365$ & $\begin{array}{l}\text { Forward: ctgtgagatgtgtgtgttggtaac } \\
\text { Reverse: tctggataagagcagtatcacctg }\end{array}$ & 58 \\
\hline CHEK2EXIO & 546 & 10 & $366-420$ & $\begin{array}{l}\text { Forward: ttaatttaagcaaaattaaatgtcc } \\
\text { Reverse: ggcatggtggtgtgcatc }\end{array}$ & 54 \\
\hline CHEK2EXII & 353 & 11 & $42 I-458$ & $\begin{array}{l}\text { Forward: gctgggattacaagcctaagg } \\
\text { Reverse: gaagaaactcccaccacagc }\end{array}$ & 69 \\
\hline CHEK2EX 12 & 541 & 12 & $459-487$ & $\begin{array}{l}\text { Forward: ggcctgttaattctggcatactc } \\
\text { Reverse: aaaggttgtagcctggccag }\end{array}$ & 67 \\
\hline CHEK2EXI3 & 488 & 13 & $488-514$ & $\begin{array}{l}\text { Forward: cctctgggaaggtagaggc } \\
\text { Reverse: caatccctagctgtgcttatcg }\end{array}$ & 66 \\
\hline CHEK2EXI4 & 585 & 14 & $515-543$ & $\begin{array}{l}\text { Forward: cccccactttactggaagc } \\
\text { Reverse: gcaaaaccctgtctctacaaaat }\end{array}$ & 64 \\
\hline CHEK2 R406H Allele Specific & $N / A$ & 10 & $\mathrm{~N} / \mathrm{A}$ & Forward: ggactgctgggtataacca & 54 \\
\hline CHEK2 Long Range & $\sim 9,200$ & $10-14$ & $366-543$ & $\begin{array}{l}\text { Forward: cgacggccagtctcaagaagaggactgtctt } \\
\text { Reverse: gctatgaccatgcacaaagcccaggttccatc }\end{array}$ & 58 \\
\hline CHEK2 Restriction & 546 & 10 & $366-420$ & Forward : ttaatttaagcaaaattaaatgtc Reverse : ggcatggtggtgtgcatc & 57 \\
\hline CHEK2 Restriction Nested & 202 & 10 & $380-420$ & $\begin{array}{l}\text { Forward: catgagaaccttatgtggaaccc } \\
\text { Reverse: cctggacaacagagcaagacacat }\end{array}$ & 58 \\
\hline CHEK2 I I00delC Sizing & 196 & 10 & $366-396$ & $\begin{array}{l}\text { Forward:aatagaaactgatctagcctacgtgt } \\
\text { Reverse: gaacttcaggcgccaagt }\end{array}$ & 60 \\
\hline
\end{tabular}

Summary of primers, annealing termperatures and PCR amplicon sizes for the 14 coding exons of CHEK2. Additional details are listed for primers used for Long Range PCR, R406H and I I00delC genotyping.

Grantham matrix score (Grantham, 1974), Grantham variation (GV) and Grantham deviation (GD). Conservation of the wild type amino acid was analyzed using the multiple sequence alignment program ClustalW. Substitution tolerance was estimated using the SIFT algorithm (ㅇorting Intolerant From Tolerant).

\section{Statistical analysis}

Allele and genotype frequency is expressed as a proportion of the entire sample set. Fisher's exact test was used to test for significance. In the circumstance where a sample would not amplify, it was excluded from all calculations. Two-tailed p values are presented.

\section{Results}

SNP discovery in CHEK2 coding regions was conducted by sequencing 25 cases and 25 controls simultaneously. This approach provides an $80 \%$ power to detect an allele with a frequency of $1 \%$ or more [26]. Furthermore, this eliminates the potential biases inherent when studying cases first and then searching for only those variants identified, in the control set. From this, we have identified two variants: the previously reported silent variant, 252A $>\mathrm{G}$ (E84E), observed in 2/25 cases versus 2/25 controls, in addition to the novel missense variant $1217 \mathrm{G}>\mathrm{A}$, which results in an amino acid substitution at position 406, of an arginine for a histidine $(\mathrm{R} 406 \mathrm{H}$, Figure 1$)$ observed in $1 / 25$ cases.

The missense mutation, $\mathrm{R} 406 \mathrm{H}$ was further screened for in extended groups of cases and controls. Through allelespecific PCR, we identified one additional affected case $(1 / 124,0.81 \%)$ from Group 2 . Group 3 was genotyped by a restriction assay and was found to contain one affected case $(1 / 543,0.18 \%)$. Within our neonatal set of controls, Group 4, R406H was observed in 22 samples (22/6432, $0.34 \%$ ). Overall, the frequency of the R406H allele was not significantly elevated in total breast cancer cases (3/ 


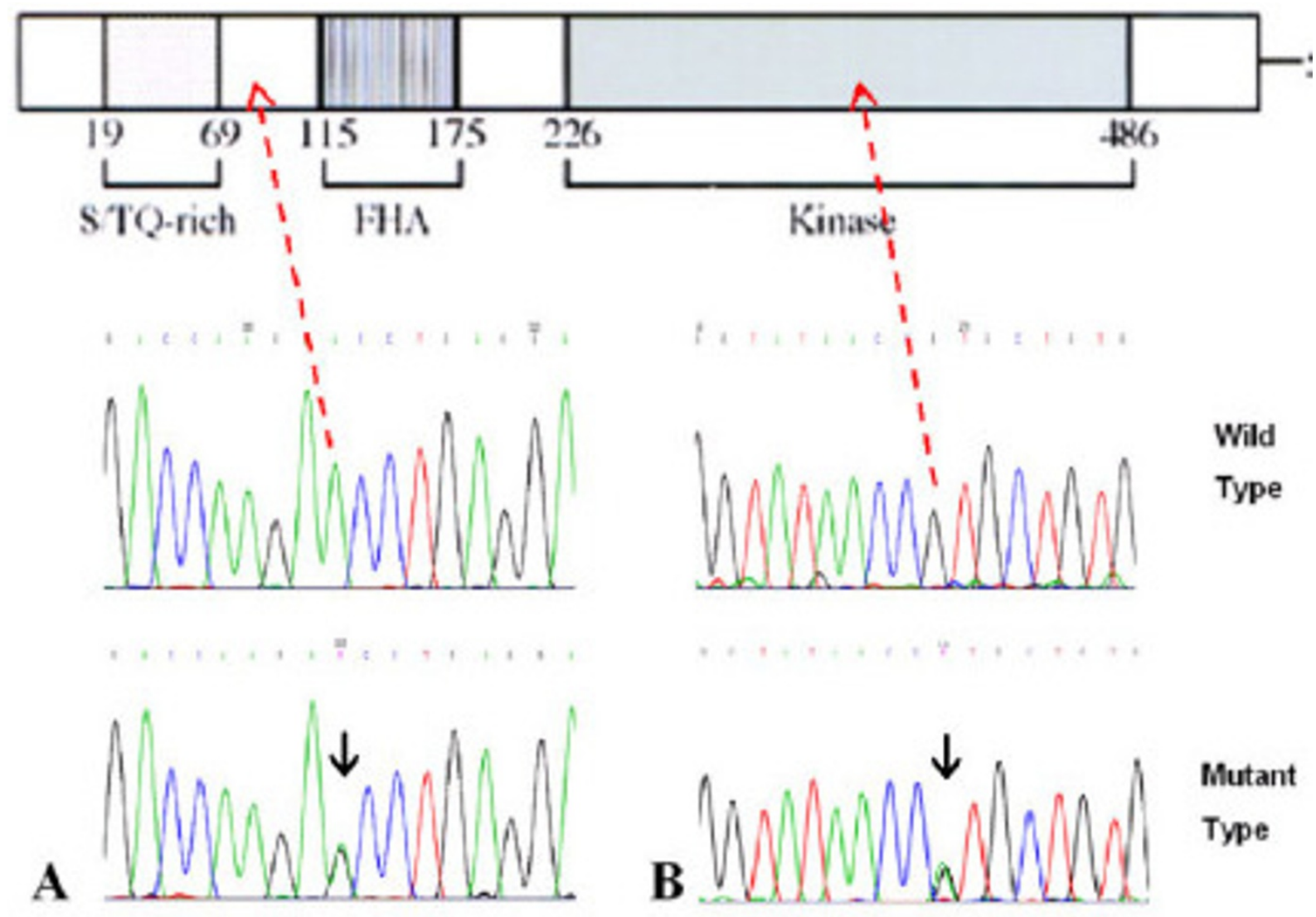

Figure I

E84E and R406H. A) Chromatogram of the silent E84E with arrow illustrating its location N' Terminal to the CHEK2 forkhead association domain. B) Chromatogram of R406H and its location within the CHEK2 Kinase domain.

692, $0.43 \%)$ compared with healthy controls (22/6573, $0.33 \%$ ) $\mathrm{P}=0.73$ (Table 2).

To predict the significance of the $\mathrm{R} 406 \mathrm{H}$ substitution, sequence alignment of CHEK2 exon 10 was analyzed across ten species, revealing a modest conservation of the arginine residue amongst higher eukaryotes, with 6/10

Table 2: CHEK2 I2I7G>A Frequency

\begin{tabular}{cccc}
\hline Group & BRCA & CTRL & P-Value \\
\hline I & $4.00 \%(1 / 25)^{*}$ & $0.00 \%(0 / 25)^{*}$ & 1.00 \\
$\mathbf{2}$ & $0.81 \%(1 / 124)^{*}$ & $0.00 \%(0 / 116)^{*}$ & 1.00 \\
$\mathbf{3}$ & $0.18 \%(1 / 543)$ & $\mathrm{N} / \mathrm{A}$ & $\mathrm{N} / \mathrm{A}$ \\
$\mathbf{4}$ & $\mathrm{N} / \mathrm{A}$ & $0.34 \%(22 / 6432)$ & $\mathrm{N} / \mathrm{A}$ \\
\hline Total & $\mathbf{0 . 4 3 \% ( 3 / 6 9 2 )}$ & $\mathbf{0 . 3 3 \% ( 2 2 / 6 5 7 3 )}$ & $\mathbf{0 . 7 3}$
\end{tabular}

*Genotyped for II00delC which was observed in 2.01\% (3/I49) of cases vs $0.7 \%(\mathrm{I} / \mathrm{I} 4 \mathrm{I})$ controls. If we compare the frequency in cases with that seen in the same neonatal controls used in this study, that were also tested for I I00delC by Zhang et al [30] (19 I I00delC carriers among 6460 controls), then the difference between cases and controls is statistically significant $(P=0.0 \mathrm{I})$. species displaying homology (Table 3). When comparing the mean chemical difference between arginine and histidine, a Grantham score of 29, GV of 124.29 and a GD of 0.0 is obtained, suggesting the neutrality of this substitution. Furthermore, tolerance of this substitution is indicated via analysis by the SIFT algorithm (SIFT score of $0.10)$.

Additionally, patients included in Group 2 were further genotyped for $1100 \mathrm{delC}$. Including the fully sequenced 25 cases and controls, 1100 delC was observed in 2.01\% (3/ 149 ) of cases versus $0.7 \%(1 / 141)$ of controls.

\section{Discussion}

Inherited breast cancer has been associated with germline mutations in more than ten different genes, most of which are involved in the maintenance of genomic integrity. A large proportion of such cases can be accounted for by mutations in the tumor suppressor genes BRCA1 and BRCA2. Additionally, TP53, PTEN, CDH1 and STK11 are considered high-risk breast cancer susceptibility genes. Mutations in ATM, BRIP1, PALB2, CHEK2 and possibly 
Table 3: Sequence Alignment of CHEK2 Exon 10

\begin{tabular}{cl}
\hline Mosquito & VSDFGSSKFLDHIFMRTICGTPEYVAPEVLESNGQKPYTRQVDVWSLGVVLYTM --256 \\
Fruit Fly & VSDFGLSKFVQKDSVMRTLCGTPLYVAPEVLITGGREAYTKKVDIWSLGVVLFTC --376 \\
Homo Sapiens & ITDFGHSKILGETSLMRTLCGTPTYLAPEVLVSVGTAGYNRAVDCWSLGVILFIC --420 \\
Chimpanzee & \\
Dog & ITDFGQSKILGETSLMRTLCGTPTYLAPEVLNSFGTAGYNRAVDCWSLGVILFIC --42I \\
Mouse & ITDFGQSKILGETSLMRTLCGTPTYLAPEVLVSNGTAGYSRAVDCWSLGVILFIC --424 \\
Rat & ITDFGQSKILGETSLMRTLCGTPTYLAPEVLISNGTAGYSRAVDCWSLGVILFIC --423 \\
Chicken & -TYFGQSKILGETSLMKTLCGTPTYLAPEVLNSFGTAGYSRAVDCWSLGVILFVC --39I \\
Fugu & VTDFNQSRILEETMLMRTLCGTPSYLAPEVFTQASTTGYSLAVDAWSLGVLLFC --396 \\
Tetraodon & VTDFNQSRILETMLMRTLCGTPSYLAPEVFTQASTSGYGLAVDAWSLGVLLFC --430 \\
C. Elegans & LTDFGMAKNSVN--RMKTHCGTPSYCAPEIVANQG-VEYTPKVDIWSLGCVLFIT --370 \\
\hline
\end{tabular}

NBS1, RAD50 are also associated with a moderately increased risk for breast cancer, and many low penetrance genes have recently been identified. However, roughly $50 \%$ of familial breast cancers remain to be elucidated $[27,28]$.

In the current study, 25 French Canadian breast cancer patients and 25 healthy controls were fully screened for variants within the CHEK2 gene. Two variants were identified: the silent variant E84E and the novel R406H missense variant. E84E, which has been reported in several other CHEK2 screens, is likely a neutral allele with no association to breast cancer $[14,29,30]$. In addition, given that the primary structure of CHEK2 is unaltered by the E84E mutation, and further, that it was observed at a similar frequency in cases and controls suggests against the possibility that this variant may affect an exonic splicing enhancer or aberrantly affect protein translation rates. Thus, no further investigation of this variant was conducted. R406H, however, was genotyped for in an extended panel of breast cancer cases and healthy controls. Neither variant was observed at a significantly high frequency in breast cancer cases when compared with controls.

To further characterize any potential impact of $\mathrm{R} 406 \mathrm{H}$, bioinformatic tools were employed. In short, conservation analysis, substitution evaluation and a tolerance test lack any indication of a pathogenic contribution from this allele.

Large international studies [10,31-33] have shown that 1100 delC is associated with increased breast cancer risk in many, but by no means all, world populations. Our findings in cases (Table 2) when combined with previous data on controls [32] suggest that this allele is also associated with breast cancer risk in the French Canadian population. The evidence that other CHEK2 alleles are associated with an increased risk in the general population is less convincing $[34,35]$. However, some founder alleles that do seem to be associated with an increased risk in specific populations have been identified.
To date, five interesting CHEK2 founder alleles have been identified, all of which are associated with an elevated risk for breast: 1100delC, I157T, IVS2 + 1G>A, S428F and del5395. All five variants have been shown to contribute to breast cancer risk provided they are present in the population of interest, with the latter three particularly being observed with high degree of ethnic specificity. The IVS2 $+1 \mathrm{G}>\mathrm{A}$ splicing mutation has been observed in the Polish population as a founder mutation with a $0.3 \%$ population frequency [36] and associates with approximately a two-fold elevated risk for breast cancer. In the Ashkenazi Jewish population, Shaag et al [14] discovered the novel missense mutation S428F (1283C $>\mathrm{T}$ ) at a frequency of $2.88 \%$ amongst 1632 breast cancer patients compared to $1.37 \%$ of 1673 controls, thus suggesting S428F is associated with breast cancer risk; a yeast complementation assay supported the hypothesis that this variant aberrantly affects CHEK2 protein function. The most recently identified founder mutation, del5395, resulting in a loss of exons 9 and 10, was originally identified in two families of Czech or Slovak origin [18]. This founder mutation has twice been studied in detail; the first observing the deletion in $1.3 \%$ of 631 breast cancer cases and $0.0 \%$ of 367 healthy controls from the Czech and Slovak Republics. In agreement with the first study, Cybulski et al [37] investigated the 5,395 bp deletion in Poland, observing the frequency to be $0.9 \%$ of 4,454 breast cancer cases versus $0.4 \%$ of 5,496 healthy controls $(\mathrm{OR}=2.0 ; 95 \% \mathrm{CI}=1.2-$ 3.4). It is likely other CHEK2 founder mutations are yet to be discovered, as to date, CHEK2 has not been thoroughly investigated in many ethnic groups.

One such group, the French Canadian population has proved to be valuable in investigations of other breast cancer susceptibility genes. For example, several common pathogenic BRCA1/2 founder mutations are recognized in the French Canadian population [21-23]. Moreover, the proposition that additional French Canadian founder mutations have yet to be revealed is supported by the recent identification of a PALB2 truncating mutation, Q775X [24]. 
The results presented here represent the first systematic analysis of CHEK2 in the French Canadian population. The novel variant we identified, $\mathrm{R} 406 \mathrm{H}$, is almost certainly not associated with increased risk for breast cancer and CHEK2 alleles other than $1100 \mathrm{delC}$ are unlikely to contribute to breast cancer risk in this population. However, the possibility that CHEK2, due to its role in cell cycle regulation, may influence the risk of other familial cancers in the French Canadian population, such as prostate, colon, ovarian or colorectal cancer, and would thus be an informative population for such future investigations. Interestingly, some of the well known variants, such as I157T have been associated with colon cancer [38], whereas the truncating variants 1100delC and IVS2 + $1 \mathrm{G}>\mathrm{A}$ have been associated with an elevated risk for familial prostate cancer in both the Polish and Finish population [16]. Most recently, all three variants in addition to the del5395 have been associated with an increased susceptibility to bladder cancer in Poland [39].

The emerging picture suggests that some functionally significant variants in CHEK2 are able to predispose cells from a wide distribution of organs to an elevated risk of cancer. Thus, much remains to be studied with respect to CHEK2 alleles in the French Canadians, but it seems unlikely that a specific, common founder mutation for breast cancer exists in this population.

\section{Conclusion}

Sequencing of the CHEK2 gene in 25 breast cancer patients and 25 healthy controls, from the French Canadian population did not reveal any pathogenic mutations. The one novel missense variant identified in this study, $\mathrm{R} 406 \mathrm{H}$, does not appear to be associated with breast cancer risk. Additional investigations of CHEK2 and French Canadian breast cancer, utilizing large panels of familial and/or sporadic cases, would be necessary to refute the notion that additional CHEK2 susceptibility alleles exist in the French Canadian population. However, it is unlikely that CHEK2 alleles other than 1100delC significantly influence familial breast cancer risk within our study group.

Note added in Proof: We have recently completed MLPA (MRC-Holland, kit P190) analysis on 41 French Canadian women with a personal and familial history breast cancer. Cases had previously been screened for all known founder BRCA1 and BRCA2 mutations, as well as CHEK2 $1100 \mathrm{delC}$. No genomic deletions or insertions were identified.

\section{Competing interests}

The authors declare that they have no competing interests.

\section{Authors' contributions}

Experimental design was conceived by DJN, LQC, NH and WDF. Data acquisition was conducted by DJN under the supervision of WDF. Initial technical optimizations were conducted by VR and NH. Sample recruitment and implementation was carried out in collaboration with PG, PT and AR. Neonatal genotyping was performed by GC and FR. Additional French Canadian R406H genotyping was carried out by SAN and PZ. DJN drafted the manuscript, which was revised by WDF. All authors have given their final approval of the version to be published.

\section{Acknowledgements}

DJN would like to thank Dr. Marc Tischkowitz for his intellectual input, patience and guidance during the drafting of this manuscript; Marius Theis for bioinformatics input; We thank Dr. George Chong for providing assistance and access to multiple molecular diagnostic utilities; Sylvie Giroux for her involvement with genotyping; Nelly Sabbaghian and Osman Ahmed for technical assistance; Banque de tissue et de données of the Récherche sur le cancer of the F.R.S.Q. for supporting the collection and distribution of some of the clinical samples from cancer families. The current study was supported by research grants to WDF from the Canadian Breast Cancer Research Alliance and the Turner Family Cancer Research Fund.

\section{References}

I. Parkin DM, Bray F, Ferlay J, Pisani P: Global cancer statistics, 2002. Ca-A Cancer Journal for Clinicians 2005, 55:74- 108.

2. Brody LC: CHEKs and balances: accounting for breast cancer. Nature Genetics 2002, 3 I:3-4.

3. Ford D, Easton DF, Stratton M, Narod S, Goldgar D, Devilee P, Bishop DT, Weber B, Lenoir G, Chang-Claude J, Sobol H, Teare MD, Struewing J, Arason A, Scherneck S, Peto J, Rebbeck TR, Tonin P, Neuhausen S, Barkardottir R, Eyfjord J, Lynch H, Ponder BA, Gayther $S A$, Zelada-Hedman $M$, .: Genetic heterogeneity and penetrance analysis of the BRCAI and BRCA2 genes in breast cancer families. The Breast Cancer Linkage Consortium. Am J Hum Genet 1998, 62:676-689.

4. Chehab NH, Malikzay A, Appel M, Halazonetis TD: Chk2/hCds I functions as a DNA damage checkpoint in $\mathbf{G}(\mathrm{I})$ by stabilizing p53. Genes \& Development 2000, I 4:278-288.

5. Lee JS, Collins KM, Brown AL, Lee CH, Chung JH: hCds I-mediated phosphorylation of BRCAI regulates the DNA damage response. Nature 2000, 404:20I-204.

6. Yang ST, Kuo C, Bisi JE, Kim MK: PML-dependent apoptosis after DNA damage is regulated by the checkpoint kinase hCds I/ Chk2. Nature Cell Biology 2002, 4:865-870.

7. Meijers-Heijboer $\mathrm{H}$, van den Ouweland A, Klijn J, Wasielewski M, de Snoo A, Oldenburg R, Hollestelle A, Houben M, Crepin E, van VeghelPlandsoen M, Elstrodt F, van Duijn C, Bartels C, Meijers C, Schutte M, McGuffog L, Thompson D, Easton DF, Sodha N, Seal S, Barfoot R, Mangion J, Chang-Claude J, Eccles D, Eeles R, Evans DG, Houlston R, Murday V, Narod S, Peretz T, Peto J, Phelan C, Zhang HX, Szabo C, Devilee P, Goldgar D, Futreal PA, Nathanson KL, Weber BL, Rahman $N$, Stratton MR: Low-penetrance susceptibility to breast cancer due to CHEK2*IIO0delC in noncarriers of BRCAI or BRCA2 mutations. Nature Genetics 2002, 3 I:55-59.

8. Vahteristo P, Bartkova J, Eerola H, Syrjakoski K, Ojala S, Kilpivaara O, Tamminen A, Kononen J, Aittomaki K, Heikkila P, Holli K, Blomqvist C, Bartek J, Kallioniemi OP, Nevanlinna H: A CHEK2 genetic variant contributing to a substantial fraction of familial breast cancer. American Journal of Human Genetics 2002, 71 :432-438.

9. Easton D, McGuffog L, Thompson D, Dunning A, Tee L, Baynes C, Healey C, Pharoah P, Ponder B, Seal S, Barfoot R, Sodha N, Eeles R, Stratton M, Rahman N, Peto J, Spurdle AB, Chen XQ, ChenevixTrench G, Hopper JL, Giles GG, McCredie MRE, Syrjakoski K, Holli K, Kallioniemi O, Eerola $H$, Vahteristo P, Blomqvist C, Nevanlinna $H$, Kataja V, Mannermaa A, Dork T, Bremer M, Devilee P, de Bock GH, Krol-Warmerdam EMM, Kroese-Jansema K, Wijers-Koster P, Cornelisse CJ, Tollenaar RAEM, Meijers-Heijboer H, Berns E, Nagel J, 
Foekens J, Klijn JGM, Schutte M: CHEK2* I I 00delC and susceptibility to breast cancer: A collaborative analysis involving 10,860 breast cancer cases and 9,065 controls from 10 studies. American Journal of Human Genetics 2004, 74: I I75-I I 82.

10. CHEK2*1I00delC and susceptibility to breast cancer: a collaborative analysis involving 10,860 breast cancer cases and 9,065 controls from 10 studies. Am J Hum Genet 2004, 74: $1175-1182$

II. Kleibl Z, Novotny J, Bezdickova D, Malik R, Kleiblova P, Foretova L, Petruzelka L, llencikova D, Cinek P, Pohlreich P: The CHEK2 c.I I 00delC germline mutation rarely contributes to breast cancer development in the Czech Republic. Breast Cance Research and Treatment 2005, 90:165-167.

12. Wagenius M, Borg A, Johansson L, Giwercman A, Bratt O: CHEK2*I I00delC is not an important high-risk gene in families with hereditary prostate cancer in southern Sweden. Scandinavian Journal of Urology and Nephrology 2006, 40:23-25.

13. Margolin S, Eiberg H, Lindblom A, Bisgaard ML: CHEK2 I I00delC is prevalent in Swedish early onset familial breast cancer. Bmc Cancer 2007, 7.

14. Shaag A, Walsh T, Renbaum P, Kirchhoff T, Nafa K, Shiovitz S, Mandell JB, Welcsh P, Lee MK, Ellis N, Offit K, Levy-Lahad E, King MC: Functional and genomic approaches reveal an ancient CHEK2 allele associated with breast cancer in the Ashkenazi Jewish population. Human Molecular Genetics 2005, 14:555-563.

15. Dong XY, Wang L, Taniguchi K, Wang XS, Cunningham JM, McDonnell SK, Qian CP, Marks AF, Slager SL, Peterson BJ, Smith BI, Cheville JC, Blute ML, Jacobsen SJ, Schaid DJ, Tindall DJ, Thibodeau SN, Liu WG: Mutations in CHEK2 associated with prostate cancer risk. American Journal of Human Genetics 2003, 72:270-280.

16. Cybulski C, Huzarski T, Gorski B, Masojc B, Mierzejewski M, Debniak T, Gliniewicz B, Matyjasik J, Zlowocka E, Kurzawski G, Sikorski A, Posmyk M, Szwiec M, Czajka R, Narod SA, Lubinski J: Novel founder CHEK2 mutation is associated with increased prostate cancer risk. Cancer Research 2004, 64:2677-2679.

17. Bogdanova N, Enssen-Dubrowinskaja N, Feshchenko S, Lazjuk GI, Rogov YI, Dammann O, Bremer M, Karstens JH, Sohn C, Dork T: Association of two mutations in the CHEK2 gene with breast cancer. International Journal of Cancer 2005, I I 6:263-266.

18. Walsh T, Casadei S, Coats KH, Swisher E, Stray SM, Higgins J, Roach KC, Mandell J, Lee MK, Ciernikova S, Foretova L, Soucek P, King MC: Spectrum of mutations in BRCAI, BRCA2, CHEK2, and TP53 in families at high risk of breast cancer. Jama-Journal of the American Medical Association 2006, 295: I379-1388.

19. Laberge AM, Michaud J, Richter A, Lemyre E, Lambert M, Brais B, Mitchell GA: Population history and its impact on medical genetics in Quebec. Clinical Genetics 2005, 68:287-30I.

20. Scriver CR: Human genetics: Lessons from Quebec populations. Annual Review of Genomics and Human Genetics 200I, 2:69-10I.

21. Tonin PN, Mes-Masson AM, Futreal PA, Morgan K, Mahon M, Foulkes WD, Cole DEC, Provencher D, Ghadirian P, Narod SA: Founder BRCAI and BRCA2 mutations in French Canadian breast and ovarian cancer families. American Journal of Human Genetics 1998, 63:|34|-|35|.

22. Oros KK, Leblanc G, Arcand SL, Shen Z, Perret C, Mes-Masson AM, Foulkes WD, Ghadirian P, Provencher D, Tonin PN: Haplotype analysis suggest common founders in carriers of the recurrent BRCA2 mutation, 3398delAAAAG, in French Canadian hereditary breast and/ovarian cancer families. Bmc Medical Genetics 2006, 7:

23. Simard J, Dumont M, Moisan AM, Gaborieau V, Vezina H, Durocher F, Chiquette J, Plante M, Avard D, Bessette P, Brousseau C, Dorval M, Godard B, Houde L, Joly Y, Lajoie MA, Leblanc G, Lepine J, Lesperance B, Malouin H, Parboosingh J, Pichette R, Provencher L, Rheaume J, Sinnett D, Samson C, Simard JC, Tranchant M, Voyer P, Easton D, Tavtigian SV, Knoppers BM, Laframboise R, Bridge P, Goldgar D: Evaluation of BRCAI and BRCA2 mutation prevalence, risk prediction models and a multistep testing approach in French-Canadian families with high risk of breast and ovarian cancer. Journal of Medical Genetics 2007, 44:107-I2I.

24. Foulkes WD, Ghadirian P, Akbari MR, Hamel N, Giroux S, Sabbaghian N, Darnel A, Royer R, Poll A, Fafard E, Robidoux A, Martin G, Bisma TA, Tischkowitz M, Rousseau F, Narod SA: Identification of a novel truncating PALB2 mutation and analysis of its contribution to early-onset breast cancer in French-Canadian women. Breast Cancer Res 2007, 9:R83.
25. Giroux S, Dube-Linteau A, Cardinal G, Labelle Y, Laflamme N, Giguere $Y$, Rousseau $F$ : Assessment of the prevalence of the 985A > G MCAD mutation in the French-Canadian population using allele-specific PCR. Clinical Genetics 2007, 7I:569-575.

26. Houlston RS, Peto J: The search for low-penetrance cancer susceptibility alleles. Oncogene 2004, 23:647I-6476.

27. Walsh T, King MC: Ten genes for inherited breast cancer. Cancer Cell 2007, I I: 103-105.

28. Campeau PM, Foulkes WD, Tischkowitz MD: Hereditary breast cancer: new genetic developments, new therapeutic avenues. Hum Genet 2008, I 24:3I-42.

29. Schutte M, Seal S, Barfoot R, Meijers-Heijboer H, Wasielewski M, Evans DG, Eccles D, Meijers C, Lohman F, Klijn J, van den Ouweland A, Futreal PA, Nathanson KL, Weber BL, Easton DF, Stratton MR, Rahman N: Variants in CHEK2 other than II00delC do not make a major contribution to breast cancer susceptibility. American Journal of Human Genetics 2003, 72: 1023-1028.

30. Bell DW, Varley JM, Szydlo TE, Kang DH, Wahrer DCR, Shannon KE, Lubratovich M, Verselis SJ, Isselbacher KJ, Fraumeni JF, Birch JM, Li FP, Garber JE, Haber DA: Heterozygous germ line hCHK2 mutations in Li-Fraumeni syndrome. Science 1999, 286:2528-253I.

31. Bell DW, Kim SH, Godwin AK, Schiripo TA, Harris PL, Haserlat SM, Wahrer DCR, Haiman CA, Daly MB, Niendorf KB, Smith MR, Sgroi DC, Garber JE, Olopade OI, Le Marchand L, Henderson BE, Altshuler $D$, Haber DA, Freedman ML: Genetic and functional analysis of CHEK2 (CHK2) variants in multiethnic cohorts. International Journal of Cancer 2007, I 21:2661-2667.

32. Zhang SY, Phelan CM, Zhang P, Rousseau F, Ghadirian P, Robidoux A, Foulkes W, Hamel N, McCready D, Trudeau M, Lynch H, Horsman D, De Matsuda MLL, Aziz Z, Gomes M, Costa MM, Liede A, Poll A, Sun P, Narod SA: Frequency of the CHEK2 I I00delC mutation among women with breast cancer: An international study. Cancer Research 2008, 68:2154-2157.

33. Weischer M, Bojesen SE, Ellervik C, Tybjaerg-Hansen A, Nordestgaard BG: CHEK2*II00delC genotyping for clinical assessment of breast cancer risk: meta-analyses of 26,000 patient cases and 27,000 controls. I Clin Oncol 2008, 26:542-548.

34. Allinen M, Huusko P, Mantyniemi S, Launonen V, Winqvist R: Mutation analysis of the CHK2 gene in families with hereditary breast cancer. British Journal of Cancer 200I, 85:209-2I2.

35. Sullivan A, Yuille M, Repellin C, Reddy A, Reelfs O, Bell A, Dunne B, Gusterson BA, Osin P, Farrell PJ, Yulug I, Evans A, Ozcelik T, Gasco $\mathrm{M}$, Crook T: Concomitant inactivation of p53 and Chk2 in breast cancer. Oncogene 2002, 21:1316-1324.

36. Cybulski C, Gorski B, Huzarski T, Masojc B, Mierzejewski M, Debniak T, Teodorczyk U, Byrski T, Gronwald J, Matyjasik J, Zlowocka E, Lenner M, Grabowska E, Nej K, Castaneda J, Medrek K, Szymanska A, Szymanska J, Kurzawski G, Suchy J, Oszurek O, Witek A, Narod SA Lubinski J: CHEK2 is a multiorgan cancer susceptibility gene. American Journal of Human Genetics 2004, 75: I I 3 I- I I 35.

37. Cybulski C, Wokolorczyk D, Huzarski T, Byrski T, Gronwald J, Gorski B, Debniak T, Masojc B, Jakubowska A, van de Wetering T, Narod SA, Lubinski J: A deletion in CHEK2 of 5,395 bp predisposes to breast cancer in Poland. Breast Cancer Research and Treatment 2007, 102:119-122.

38. Kilpivaara $O$, Alhopuro $P$, Vahteristo $P$, Aaltonen LA, Nevanlinna $\mathrm{H}$ : CHEK2 II 57T associates with familial and sporadic colorectal cancer. Journal of Medical Genetics 2006, 43:.

39. Zlowocka E, Cybulski C, Gorski B, Debniak T, Slojewski M, Wokolorczyk D, Serrano-Fernandez P, Matyjasik J, van de Wetering T, Sikorski $A$, Scott RJ, Lubinski J: Germline mutations in the CHEK2 kinase gene are associated with an increased risk of bladder cancer. International Journal of Cancer 2008, I 22:583-586.

\section{Pre-publication history}

The pre-publication history for this paper can be accessed here:

http://www.biomedcentral.com/1471-2407/8/239/pre pub 